\title{
Some Properties of Line and Column Operations on Matrices
}

\author{
Xiquan Liang \\ Qingdao University of Science \\ and Technology \\ China
}

\author{
Tao Sun \\ Qingdao University of Science \\ and Technology \\ China
}

\author{
Dahai $\mathrm{Hu}$ \\ Qingdao University of Science \\ and Technology \\ China
}

\begin{abstract}
Summary. This article describes definitions of elementary operations about matrix and their main properties.
\end{abstract}

MML identifier: MATRIX12, version: 7.8.05 4.87.985

The articles [8], [13], [17], [11], [1], [18], [5], [6], [2], [7], [15], [16], [9], [10], [20], [4], [3], [21], [12], [14], and [19] provide the notation and terminology for this paper.

For simplicity, we adopt the following convention: $j, k, l, n, m, i$ are natural numbers, $K$ is a field, $a$ is an element of $K, M, M_{1}$ are matrices over $K$ of dimension $n \times m$, and $A$ is a matrix over $K$ of dimension $n$.

Let us consider $n, m$, let us consider $K$, let $M$ be a matrix over $K$ of dimension $n \times m$, and let $l, k$ be natural numbers. The functor InterchangeLine $(M, l, k)$ yielding a matrix over $K$ of dimension $n \times m$ is defined by the conditions (Def. 1).

(Def. 1)(i) len InterchangeLine $(M, l, k)=$ len $M$, and

(ii) for all $i, j$ such that $i \in \operatorname{dom} M$ and $j \in \operatorname{Seg}$ width $M$ holds if $i=l$, then (InterchangeLine $(M, l, k))_{i, j}=M_{k, j}$ and if $i=k$, then (InterchangeLine $(M, l, k))_{i, j}=M_{l, j}$ and if $i \neq l$ and $i \neq k$, then (InterchangeLine $(M, l, k))_{i, j}=M_{i, j}$. 
The following three propositions are true:

(1) For all matrices $M_{1}, M_{2}$ over $K$ of dimension $n \times m$ holds width $M_{1}=$ width $M_{2}$.

(2) Let given $M, M_{1}, i$ such that $l \in \operatorname{dom} M$ and $k \in \operatorname{dom} M$ and $i \in \operatorname{dom} M$ and $M_{1}=$ InterchangeLine $(M, l, k)$. Then

(i) if $i=l$, then $\operatorname{Line}\left(M_{1}, i\right)=\operatorname{Line}(M, k)$,

(ii) if $i=k$, then $\operatorname{Line}\left(M_{1}, i\right)=\operatorname{Line}(M, l)$, and

(iii) if $i \neq l$ and $i \neq k$, then Line $\left(M_{1}, i\right)=\operatorname{Line}(M, i)$.

(3) For all $a, i, j, M$ such that $i \in \operatorname{dom} M$ and $j \in \operatorname{Seg}$ width $M$ holds $(a \cdot \operatorname{Line}(M, i))(j)=a \cdot M_{i, j}$.

Let us consider $n, m$, let us consider $K$, let $M$ be a matrix over $K$ of dimension $n \times m$, let $l$ be a natural number, and let $a$ be an element of $K$. The functor ScalarXLine $(M, l, a)$ yields a matrix over $K$ of dimension $n \times m$ and is defined by the conditions (Def. 2).

(Def. 2)(i) len ScalarXLine $(M, l, a)=\operatorname{len} M$, and

(ii) for all $i, j$ such that $i \in \operatorname{dom} M$ and $j \in \operatorname{Seg}$ width $M$ holds if $i=l$, then $(\operatorname{ScalarXLine}(M, l, a))_{i, j}=a \cdot M_{l, j}$ and if $i \neq l$, then $(\operatorname{ScalarXLine}(M, l, a))_{i, j}=M_{i, j}$.

We now state the proposition

(4) If $l \in \operatorname{dom} M$ and $i \in \operatorname{dom} M$ and $a \neq 0_{K}$ and $M_{1}=$ ScalarXLine $(M, l, a)$, then if $i=l$, then $\operatorname{Line}\left(M_{1}, i\right)=a \cdot \operatorname{Line}(M, l)$ and if $i \neq l$, then Line $\left(M_{1}, i\right)=\operatorname{Line}(M, i)$.

Let us consider $n, m$, let us consider $K$, let $M$ be a matrix over $K$ of dimension $n \times m$, let $l, k$ be natural numbers, and let $a$ be an element of $K$. Let us assume that $l \in \operatorname{dom} M$ and $k \in \operatorname{dom} M$. The functor RlineXScalar $(M, l, k, a)$ yielding a matrix over $K$ of dimension $n \times m$ is defined by the conditions (Def. 3).

(Def. 3)(i) len RlineXScalar $(M, l, k, a)=$ len $M$, and

(ii) for all $i, j$ such that $i \in \operatorname{dom} M$ and $j \in \operatorname{Seg}$ width $M$ holds if $i=$ $l$, then (RlineXScalar $(M, l, k, a))_{i, j}=a \cdot M_{k, j}+M_{l, j}$ and if $i \neq l$, then $(\operatorname{RlineXScalar}(M, l, k, a))_{i, j}=M_{i, j}$.

We now state the proposition

(5) If $l \in \operatorname{dom} M$ and $k \in \operatorname{dom} M$ and $i \in \operatorname{dom} M$ and $M_{1}=$ RlineXScalar $(M, l, k, a)$, then if $i=l$, then Line $\left(M_{1}, i\right)=a \cdot \operatorname{Line}(M, k)+$ $\operatorname{Line}(M, l)$ and if $i \neq l$, then $\operatorname{Line}\left(M_{1}, i\right)=\operatorname{Line}(M, i)$.

Let us consider $n, m$, let us consider $K$, let $M$ be a matrix over $K$ of dimension $n \times m$, and let $l, k$ be natural numbers. We introduce $\operatorname{ILine}(M, l, k)$ as a synonym of InterchangeLine $(M, l, k)$.

Let us consider $n, m$, let us consider $K$, let $M$ be a matrix over $K$ of dimension $n \times m$, let $l$ be a natural number, and let $a$ be an element of $K$. We 
introduce $\operatorname{SXLine}(M, l, a)$ as a synonym of $\operatorname{ScalarXLine}(M, l, a)$.

Let us consider $n, m$, let us consider $K$, let $M$ be a matrix over $K$ of dimension $n \times m$, let $l, k$ be natural numbers, and let $a$ be an element of $K$. We introduce $\operatorname{RLineXS}(M, l, k, a)$ as a synonym of $\operatorname{RlineXScalar}(M, l, k, a)$.

We now state several propositions:

(6) If $l \in \operatorname{dom}\left(\left(\begin{array}{ccc}1 & & 0 \\ & \ddots & \\ 0 & & 1\end{array}\right)_{K}^{n \times n}\right)$ and $k \in \operatorname{dom}\left(\left(\begin{array}{lll}1 & & 0 \\ & \ddots & \\ 0 & & 1\end{array}\right)_{K}^{n \times n}\right)$, then $\operatorname{ILine}\left(\left(\begin{array}{ccc}1 & & 0 \\ & \ddots & \\ 0 & & 1\end{array}\right)_{K}^{n \times n}, l, k\right) \cdot A=\operatorname{ILine}(A, l, k)$.

(7) For all $l, a, A$ such that $l \in \operatorname{dom}\left(\left(\begin{array}{lll}1 & & 0 \\ & \ddots & \\ 0 & & 1\end{array}\right)_{K}^{n \times n}\right.$ ) and $a \neq 0_{K}$ holds $\operatorname{SXLine}\left(\left(\begin{array}{ccc}1 & & 0 \\ & \ddots & \\ 0 & & 1\end{array}\right)_{K}^{n \times n}, l, a\right) \cdot A=\operatorname{SXLine}(A, l, a)$.

(8) If $l \in \operatorname{dom}\left(\left(\begin{array}{lll}1 & & 0 \\ & \ddots & \\ 0 & & 1\end{array}\right)_{K}^{n \times n}\right)$ and $k \in \operatorname{dom}\left(\left(\begin{array}{lll}1 & & 0 \\ & \ddots & \\ 0 & & 1\end{array}\right)_{K}^{n \times n}\right)$, then $\operatorname{RLineXS}\left(\left(\begin{array}{ccc}1 & & 0 \\ & \ddots & \\ 0 & & 1\end{array}\right)_{K}^{n \times n}, l, k, a\right) \cdot A=\operatorname{RLineXS}(A, l, k, a)$.

(9) $\operatorname{ILine}(M, k, k)=M$.

(10) $\operatorname{ILine}(M, l, k)=\operatorname{ILine}(M, k, l)$.

(11) If $l \in \operatorname{dom} M$ and $k \in \operatorname{dom} M$, then $\operatorname{ILine}(\operatorname{ILine}(M, l, k), l, k)=M$.

(12) If $l \in \operatorname{dom}\left(\left(\begin{array}{ccc}1 & & 0 \\ & \ddots & \\ 0 & & 1\end{array}\right)_{K}^{n \times n}\right)$ and $k \in \operatorname{dom}\left(\left(\begin{array}{lll}1 & & 0 \\ & \ddots & \\ 0 & & 1\end{array}\right)_{K}^{n \times n}\right.$, then $\operatorname{ILine}\left(\left(\begin{array}{ccc}1 & & 0 \\ & \ddots & \\ 0 & & 1\end{array}\right)_{K}^{n \times n}, l, k\right)$ is invertible and

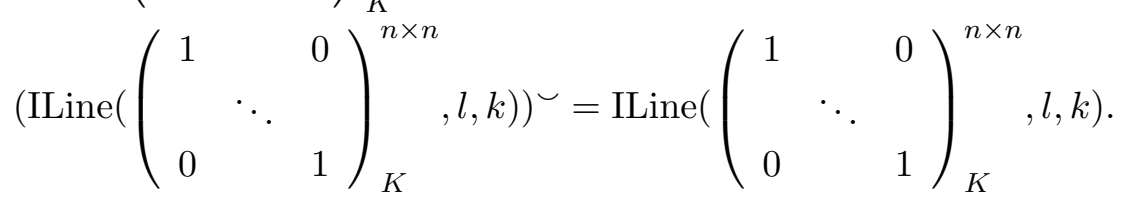


(13)

If $l \in \operatorname{dom}\left(\left(\begin{array}{lll}1 & & 0 \\ & \ddots & \\ 0 & & 1\end{array}\right)_{K}^{n \times n}\right)$ and $k \in \operatorname{dom}\left(\left(\begin{array}{lll}1 & & 0 \\ & \ddots & \\ 0 & & 1\end{array}\right)_{K}^{n \times n}\right)$ and $k \neq l$, then $\operatorname{RLineXS}\left(\left(\begin{array}{ccc}1 & & 0 \\ & \ddots & \\ 0 & & 1\end{array}\right)_{K}^{n \times n}, l, k, a\right)$ is invertible and $\left(\operatorname{RLineXS}\left(\left(\begin{array}{ccc}1 & & 0 \\ & \ddots & \\ 0 & & 1\end{array}\right)_{K}^{n \times n}, l, k, a\right)\right)^{\smile}=\operatorname{RLineXS}\left(\left(\begin{array}{ccc}1 & & 0 \\ & \ddots & \\ 0 & & 1\end{array}\right)_{K}^{n \times n}\right.$, $l, k,-a)$.

(14)

If $l \in \operatorname{dom}\left(\left(\begin{array}{ccc}1 & & 0 \\ & \ddots & \\ 0 & & 1\end{array}\right)_{K}^{n \times n}\right)$ and $a \neq 0_{K}$, then

$\operatorname{SXLine}\left(\left(\begin{array}{ccc}1 & & 0 \\ & \ddots & \\ 0 & & 1\end{array}\right)_{K}^{n \times n}, l, a\right)$ is invertible and

$\left(\operatorname{SXLine}\left(\left(\begin{array}{ccc}1 & & 0 \\ & \ddots & \\ 0 & & 1\end{array}\right)_{K}^{n \times n}, l, a\right)\right)^{\smile}=\operatorname{SXLine}\left(\left(\begin{array}{ccc}1 & & 0 \\ & \ddots & \\ 0 & & 1\end{array}\right)_{K}^{n \times n}, l, a^{-1}\right)$.

Let us consider $n, m$, let us consider $K$, let $M$ be a matrix over $K$ of dimension $n \times m$, and let $l, k$ be natural numbers. Let us assume that $l \in \operatorname{Seg}$ width $M$ and $k \in \operatorname{Seg}$ width $M$ and $n>0$ and $m>0$. The functor $\operatorname{InterchangeCol}(M, l, k)$ yields a matrix over $K$ of dimension $n \times m$ and is defined by the conditions (Def. 4).

(Def. 4)(i) len InterchangeCol $(M, l, k)=$ len $M$, and

(ii) for all $i, j$ such that $i \in \operatorname{dom} M$ and $j \in \operatorname{Seg}$ width $M$ holds if $j=l$, then $(\operatorname{InterchangeCol}(M, l, k))_{i, j}=M_{i, k}$ and if $j=k$, then (InterchangeCol $(M, l, k))_{i, j}=M_{i, l}$ and if $j \neq l$ and $j \neq k$, then (Interchange $\operatorname{Col}(M, l, k))_{i, j}=M_{i, j}$.

Let us consider $n, m$, let us consider $K$, let $M$ be a matrix over $K$ of dimension $n \times m$, let $l$ be a natural number, and let $a$ be an element of $K$. Let us assume that $l \in \operatorname{Seg}$ width $M$ and $n>0$ and $m>0$. The functor ScalarXCol $(M, l, a)$ yielding a matrix over $K$ of dimension $n \times m$ is defined by the conditions (Def. 5 ).

(Def. 5)(i) len ScalarXCol $(M, l, a)=\operatorname{len} M$, and

(ii) for all $i, j$ such that $i \in \operatorname{dom} M$ and $j \in \operatorname{Seg}$ width $M$ holds if $j=l$, then $(\operatorname{ScalarXCol}(M, l, a))_{i, j}=a \cdot M_{i, l}$ and if $j \neq l$, then $(\operatorname{ScalarXCol}(M, l, a))_{i, j}=M_{i, j}$. 
Let us consider $n, m$, let us consider $K$, let $M$ be a matrix over $K$ of dimension $n \times m$, let $l, k$ be natural numbers, and let $a$ be an element of $K$. Let us assume that $l \in \operatorname{Seg}$ width $M$ and $k \in \operatorname{Seg}$ width $M$ and $n>0$ and $m>0$. The functor RcolXScalar $(M, l, k, a)$ yielding a matrix over $K$ of dimension $n \times$ $m$ is defined by the conditions (Def. 6).

(Def. 6)(i) len RcolXScalar $(M, l, k, a)=\operatorname{len} M$, and

(ii) for all $i, j$ such that $i \in \operatorname{dom} M$ and $j \in \operatorname{Seg}$ width $M$ holds if $j=$ $l$, then $(\operatorname{RcolXScalar}(M, l, k, a))_{i, j}=a \cdot M_{i, k}+M_{i, l}$ and if $j \neq l$, then $(\operatorname{RcolXScalar}(M, l, k, a))_{i, j}=M_{i, j}$.

Let us consider $n, m$, let us consider $K$, let $M$ be a matrix over $K$ of dimension $n \times m$, and let $l, k$ be natural numbers. We introduce $\operatorname{ICol}(M, l, k)$ as a synonym of InterchangeCol $(M, l, k)$.

Let us consider $n, m$, let us consider $K$, let $M$ be a matrix over $K$ of dimension $n \times m$, let $l$ be a natural number, and let $a$ be an element of $K$. We introduce $\operatorname{SXCol}(M, l, a)$ as a synonym of $\operatorname{ScalarXCol}(M, l, a)$.

Let us consider $n, m$, let us consider $K$, let $M$ be a matrix over $K$ of dimension $n \times m$, let $l, k$ be natural numbers, and let $a$ be an element of $K$. We introduce $\operatorname{RColXS}(M, l, k, a)$ as a synonym of $\operatorname{RcolXScalar}(M, l, k, a)$.

We now state several propositions:

(15) If $l \in \operatorname{Seg}$ width $M$ and $k \in \operatorname{Seg}$ width $M$ and $n>0$ and $m>0$ and $M_{1}=M^{\mathrm{T}}$, then $\left(\operatorname{ILine}\left(M_{1}, l, k\right)\right)^{\mathrm{T}}=\operatorname{ICol}(M, l, k)$.

(16) If $l \in \operatorname{Seg}$ width $M$ and $a \neq 0_{K}$ and $n>0$ and $m>0$ and $M_{1}=M^{\mathrm{T}}$, then $\left(\operatorname{SXLine}\left(M_{1}, l, a\right)\right)^{\mathrm{T}}=\operatorname{SXCol}(M, l, a)$.

(17) If $l \in \operatorname{Seg}$ width $M$ and $k \in \operatorname{Seg}$ width $M$ and $n>0$ and $m>0$ and $M_{1}=M^{\mathrm{T}}$, then $\left(\operatorname{RLineXS}\left(M_{1}, l, k, a\right)\right)^{\mathrm{T}}=\operatorname{RColXS}(M, l, k, a)$.

(18) If $l \in \operatorname{dom}\left(\left(\begin{array}{ccc}1 & & 0 \\ & \ddots & \\ 0 & & 1\end{array}\right)_{K}^{n \times n}\right)$ and $k \in \operatorname{dom}\left(\left(\begin{array}{ccc}1 & & 0 \\ & \ddots & \\ 0 & & 1\end{array}\right)_{K}^{n \times n}\right.$ ) and $n>0$, then $A \cdot \operatorname{ICol}\left(\left(\begin{array}{ccc}1 & & 0 \\ & \ddots & \\ 0 & & 1\end{array}\right)_{K}^{n \times n}, l, k\right)=\operatorname{ICol}(A, l, k)$.

(19) If $l \in \operatorname{dom}\left(\left(\begin{array}{ccc}1 & & 0 \\ & \ddots & \\ 0 & & 1\end{array}\right)_{K}^{n \times n}\right)$ and $a \neq 0_{K}$ and $n>0$, then $A$. $\operatorname{SXCol}\left(\left(\begin{array}{ccc}1 & & 0 \\ & \ddots & \\ 0 & & 1\end{array}\right)_{K}^{n \times n}, l, a\right)=\operatorname{SXCol}(A, l, a)$. 
(20) If $l \in \operatorname{dom}\left(\left(\begin{array}{ccc}1 & & 0 \\ & \ddots & \\ 0 & & 1\end{array}\right)_{K}^{n \times n}\right)$ and $k \in \operatorname{dom}\left(\left(\begin{array}{ccc}1 & & 0 \\ & \ddots & \\ 0 & & 1\end{array}\right)_{K}^{n \times n}\right.$ ) and $n>0$, then $A \cdot \operatorname{RColXS}\left(\left(\begin{array}{lll}1 & & 0 \\ & \ddots & \\ 0 & & 1\end{array}\right)_{K}^{n \times n}, l, k, a\right)=\operatorname{RColXS}(A, l, k, a)$.

(21) If $l \in \operatorname{dom}\left(\left(\begin{array}{ccc}1 & & 0 \\ & \ddots & \\ 0 & & 1\end{array}\right)_{K}^{n \times n}\right)$ and $k \in \operatorname{dom}\left(\left(\begin{array}{ccc}1 & & 0 \\ & \ddots & \\ 0 & & 1\end{array}\right)_{K}^{n \times n}\right)$ and

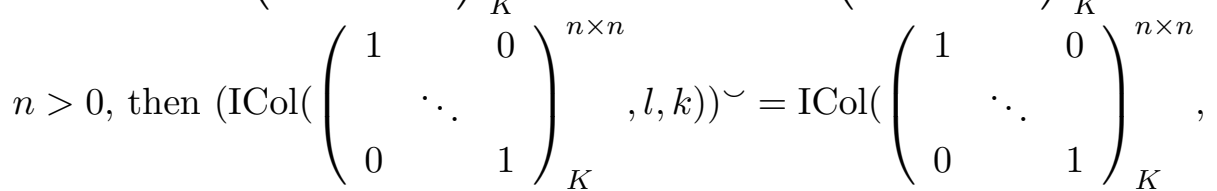
$l, k)$.

(22)

If $l \in \operatorname{dom}\left(\left(\begin{array}{ccc}1 & & 0 \\ & \ddots & \\ 0 & & 1\end{array}\right)_{K}^{n \times n}\right)$ and $k \in \operatorname{dom}\left(\left(\begin{array}{lll}1 & & 0 \\ & \ddots & \\ 0 & & 1\end{array}\right)_{K}^{n \times n}\right)$ and $k \neq l$ and $n>0$, then $\left(\operatorname{RColXS}\left(\left(\begin{array}{lll}1 & & 0 \\ & \ddots & \\ 0 & & 1\end{array}\right)_{K}^{n \times n}, l, k, a\right)\right)^{\smile}=$ $\operatorname{RColXS}\left(\left(\begin{array}{ccc}1 & & 0 \\ & \ddots & \\ 0 & & 1\end{array}\right)_{K}^{n \times n}, l, k,-a\right)$

(23) If $l \in \operatorname{dom}\left(\left(\begin{array}{ccc}1 & & 0 \\ & \ddots & \\ 0 & & 1\end{array}\right)_{K}^{n \times n}\right)$ and $a \neq 0_{K}$ and $n>0$, then $\left(\operatorname{SXCol}\left(\left(\begin{array}{ccc}1 & & 0 \\ & \ddots & \\ 0 & & 1\end{array}\right)_{K}^{n \times n}, l, a\right)\right)^{\smile}=\operatorname{SXCol}\left(\left(\begin{array}{lll}1 & & 0 \\ & \ddots & \\ 0 & & 1\end{array}\right)_{K}^{n \times n}, l, a^{-1}\right)$.

\section{REFERENCES}

[1] Grzegorz Bancerek. The ordinal numbers. Formalized Mathematics, 1(1):91-96, 1990.

[2] Grzegorz Bancerek and Krzysztof Hryniewiecki. Segments of natural numbers and finite sequences. Formalized Mathematics, 1(1):107-114, 1990.

[3] Czesław Byliński. Binary operations applied to finite sequences. Formalized Mathematics, 1(4):643-649, 1990.

[4] Czesław Byliński. Finite sequences and tuples of elements of a non-empty sets. Formalized Mathematics, 1(3):529-536, 1990. 
[5] Czesław Byliński. Functions and their basic properties. Formalized Mathematics, 1(1):5565, 1990.

[6] Czesław Byliński. Functions from a set to a set. Formalized Mathematics, 1(1):153-164, 1990.

[7] Czesław Byliński. Some basic properties of sets. Formalized Mathematics, 1(1):47-53, 1990.

[8] Katarzyna Jankowska. Matrices. Abelian group of matrices. Formalized Mathematics, 2(4):475-480, 1991.

[9] Eugeniusz Kusak, Wojciech Leończuk, and Michał Muzalewski. Abelian groups, fields and vector spaces. Formalized Mathematics, 1(2):335-342, 1990.

[10] Michał Muzalewski. Construction of rings and left-, right-, and bi-modules over a ring. Formalized Mathematics, 2(1):3-11, 1991.

[11] Andrzej Trybulec. Subsets of complex numbers. To appear in Formalized Mathematics.

[12] Andrzej Trybulec. Binary operations applied to functions. Formalized Mathematics, 1(2):329-334, 1990.

[13] Andrzej Trybulec. Tarski Grothendieck set theory. Formalized Mathematics, 1(1):9-11, 1990.

[14] Wojciech A. Trybulec. Binary operations on finite sequences. Formalized Mathematics, 1(5):979-981, 1990.

[15] Wojciech A. Trybulec. Groups. Formalized Mathematics, 1(5):821-827, 1990.

[16] Wojciech A. Trybulec. Vectors in real linear space. Formalized Mathematics, 1(2):291296, 1990.

[17] Zinaida Trybulec. Properties of subsets. Formalized Mathematics, 1(1):67-71, 1990.

[18] Edmund Woronowicz. Relations and their basic properties. Formalized Mathematics, 1(1):73-83, 1990.

[19] Xiaopeng Yue, Xiquan Liang, and Zhongpin Sun. Some properties of some special matrices. Formalized Mathematics, 13(4):541-547, 2005.

[20] Katarzyna Zawadzka. The sum and product of finite sequences of elements of a field. Formalized Mathematics, 3(2):205-211, 1992.

[21] Katarzyna Zawadzka. The product and the determinant of matrices with entries in a field. Formalized Mathematics, 4(1):1-8, 1993.

Received August 13, 2007 